Rodrigo Pestana Cunha Telles

\title{
PROJETO DE DIMENSIONAMENTO E CONSTRUÇÃO DE UM CONDICIONADOR DE COMBUSTÍVEL
}

(SIZING AND CONSTRUCTION OF A FUEL CONDITIONER)

\begin{abstract}
Trabalho de Conclusão de Curso apresentado como exigência para obtenção do título de Bacharel em Engenharia Mecânica pela Pontifícia Universidade Católica do Rio de Janeiro (PUC-Rio).
\end{abstract}

Orientador:

Sergio Leal Braga, Doutor, PUC-Rio, Brasil.

Rio de Janeiro / RJ 


\section{RESUMO}

O presente Trabalho de Conclusão de Curso tem como motivação o desenvolvimento de um trocador de calor simples e de baixo custo para ser utilizado em um Sistema Condicionador de Combustível. Após uma revisão teórica dos conceitos fundamentais envolvidos com o dimensionamento de trocadores de calor e da norma NBR ISO1585 (Veículos Rodoviários Código de ensaio de Motores - Potência Líquida Efetiva), definição do material e da construção do equipamento, montou-se uma estação de testes no Laboratório de Engenharia Veicular (LEV PUC-Rio) para que os mesmos fossem realizados. Os resultados são debatidos e apresentados ao final do texto.

Palavras-chave: Condicionador de Combustivel. Trocador de Calor. Transferência de Calor. 


\begin{abstract}
This term paper is motivated by the development of a simple heat exchanger and low cost for use in a fuel conditioner system. After a theoretical review of the fundamental concepts involved with the design of heat exchangers and the NBR ISO1585 (Road Vehicles - Engine test code - Effective Radiated Power Net), definition of the material and construction of the equipment, it rode a station of tests at the Vehicle Engineering Laboratory (LEV PUC-Rio) so that they were carried out. The results are discussed and presented in the end of text.
\end{abstract}

Key-words: Fuel conditioner. Heat exchanger. Heat transfer. 


\section{ÍNDICE DE FIGURAS}

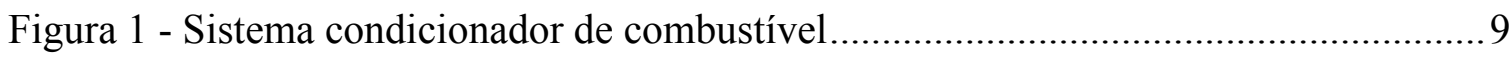

Figura 2 - Esquema da parede de um trocador ........................................................... 10

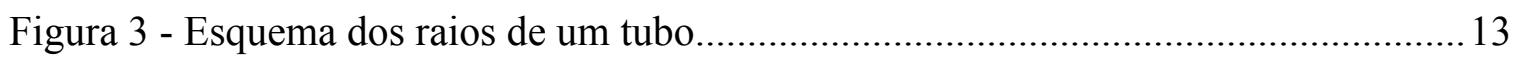

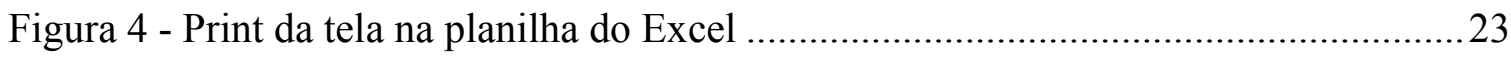

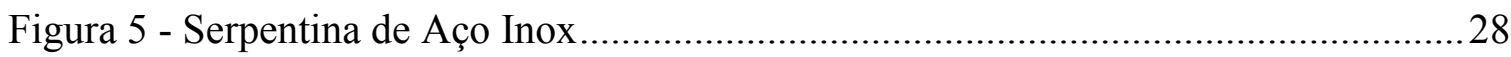

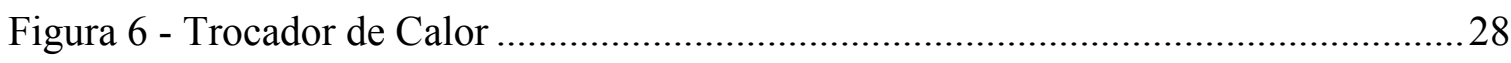

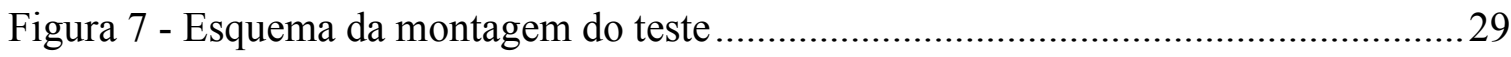

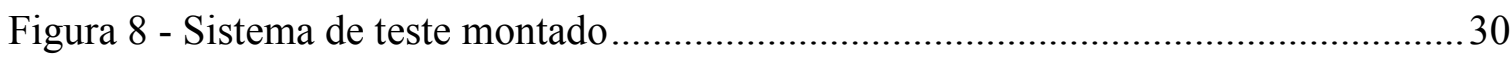

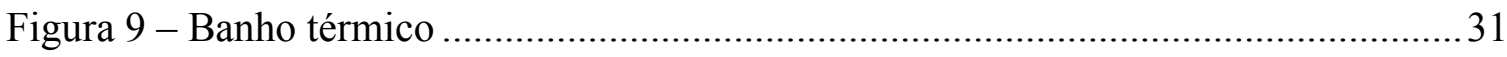

Figura 10 - Válvula Solenóide, conexão em T e válvula de gaveta (Torneira) .................. 31

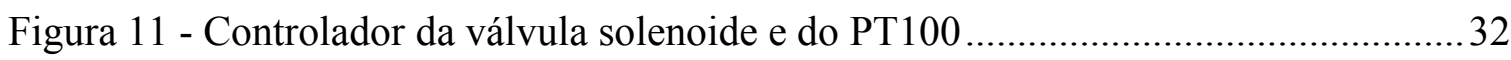

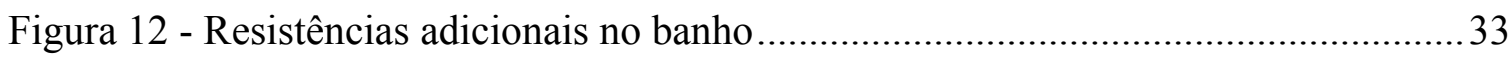

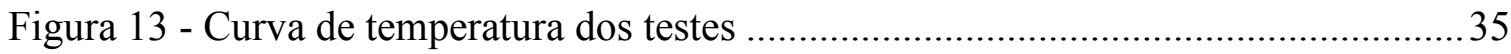

Figura 14 - Gráfico de temperatura experimental e teórica ................................................ 36 


\section{ÍNDICE DE TABELAS}

Tabela 1 - Coeficientes para Nusselt propostos por Morgan .......................................25

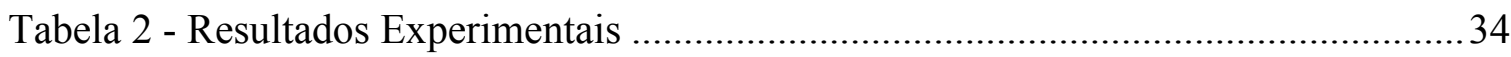

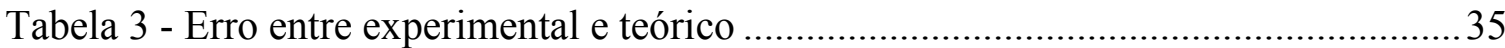




\section{SUMÁRIO}

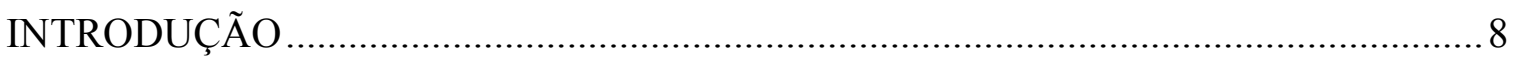

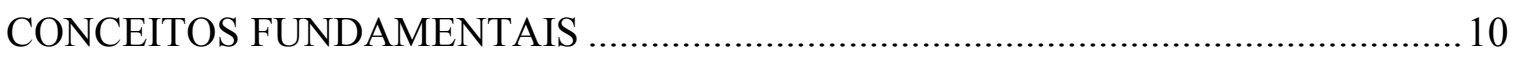

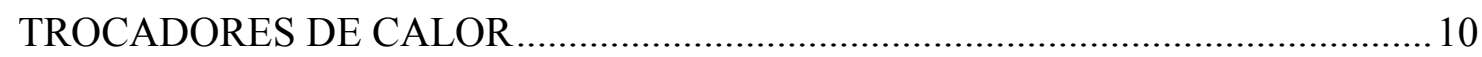

Transferência de Calor por Condução ................................................................... 12

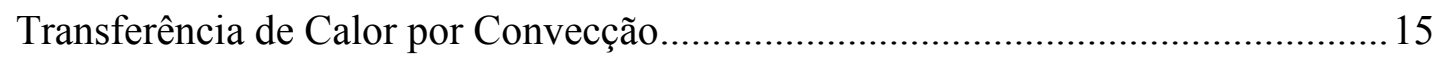

Dedução do Coeficiente Global de Transferência de Calor para Tubos ..................... 16

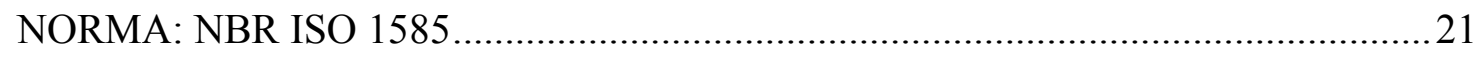

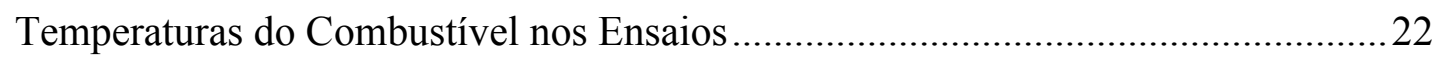

DISPOSITIVO EXPERIMENTAL E PROCEDIMENTOS .............................................23

MÉTODOS E PLANILHA UTILIZADOS PARA O DIMENSIONAMENTO............23

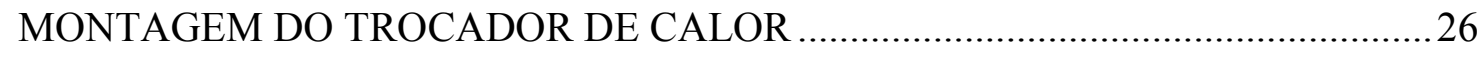

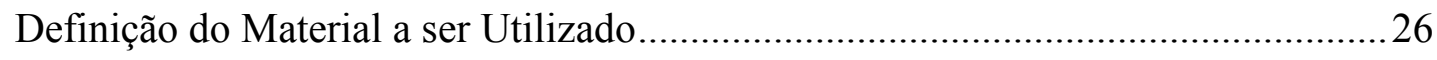

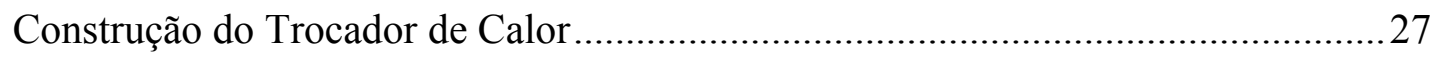

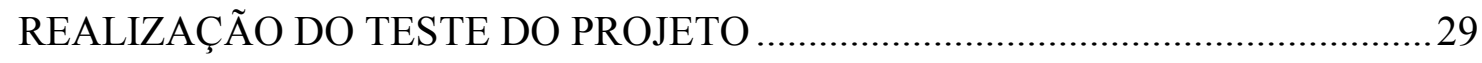

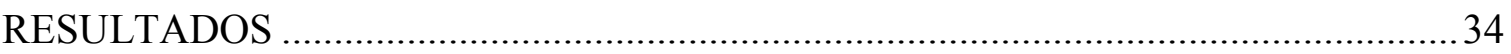

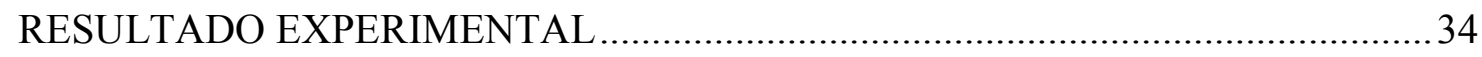

COMPARAÇÃO ENTRE RESULTADO TEÓRICO E EXPERIMENTAL ..................35 
CONCLUSÃO

BIBLIOGRAFIA ...

38 


\section{INTRODUÇÃO}

Os sistemas condicionadores de combustível têm como função manter temperatura e pressão adequadas para a realização de testes em combustíveis líquidos. São equipamentos compostos por diversos componentes mecânicos, elétricos e eletrônicos, que permite a realização de testes em laboratório de motores, obedecendo a normas técnicas.

Para dimensionar o condicionador de combustível, é necessário dimensionar o trocador de calor de mesmo, e essa é a etapa contemplada neste trabalho. Visto que é o único componente do sistema que não é um equipamento comercial.

No Brasil, a norma técnica que contempla os testes em motores de combustão interna tanto por centelha, quanto por ignição, é a NBR ISO 1585: Veículos Rodoviários - Código de ensaio de motores - Potência líquida efetiva.

Para construir o trocador de calor do condicionador de combustível, fez-se necessário o uso de 13 metros de serpentina de aço inoxidável, com 3/8" de diâmetro interno do tubo. Para se chegar a esse valor, foi necessário fazer uma simulação por meio de processos iterativos utilizando o Microsoft Office Excel.

Abaixo se pode verificar um desenho completo de um sistema condicionador de combustível com o motor e sistema de arrefecimento montados, onde o trocador de calor do combustível é o que está sendo abordado no trabalho. 


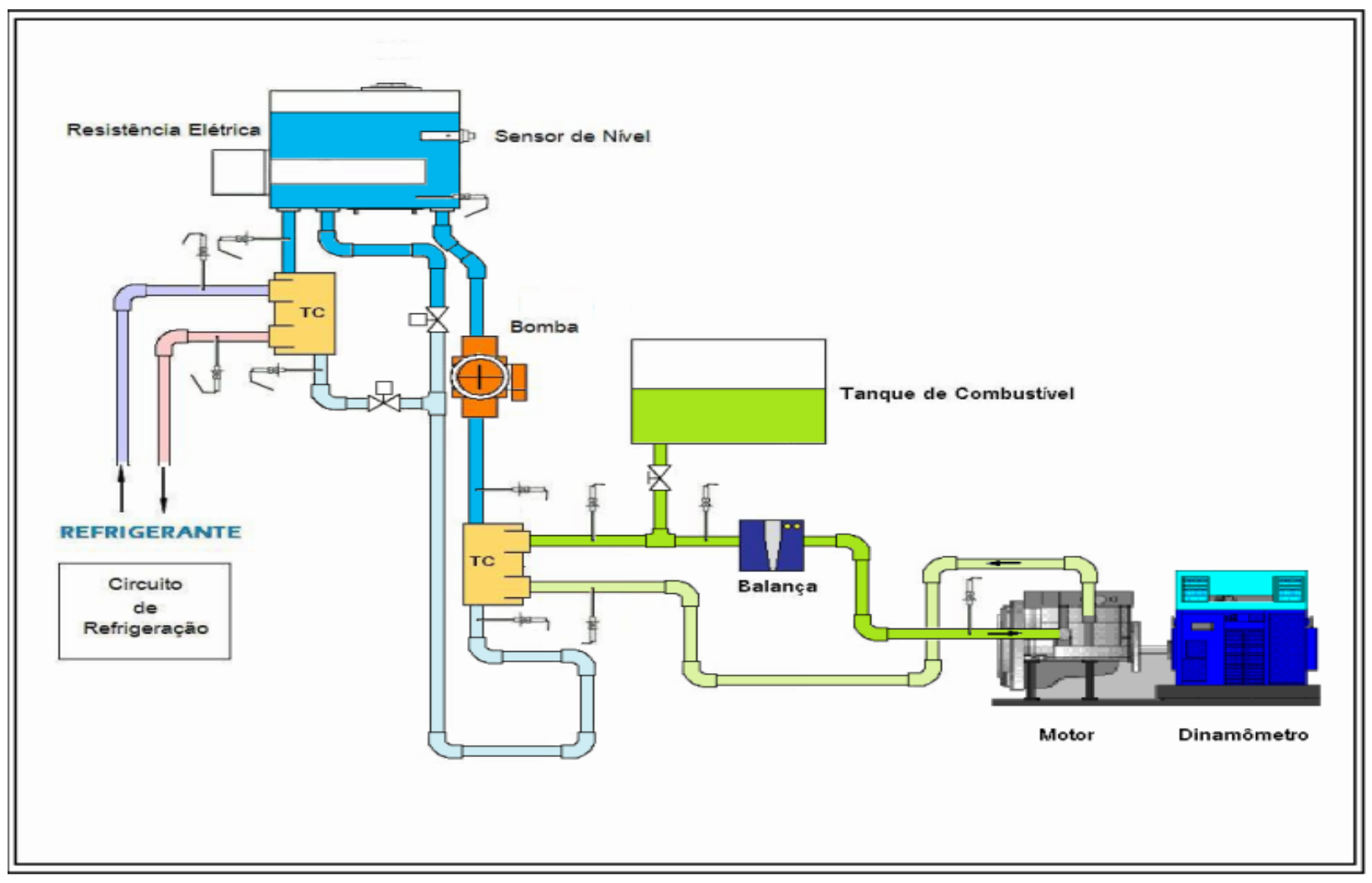

Figura 1 - Sistema condicionador de combustível 


\section{CONCEITOS FUNDAMENTAIS}

\section{TROCADORES DE CALOR}

Neste capítulo, estão abordados os conceitos fundamentais necessários para se dimensionar trocadores de calor. Imaginemos em um trocador de calor qualquer, uma parede que separa dois fluidos. Sendo assim, temos transferência de calor por convecção nos dois lados da parede e transferência de calor por condução pelo seu interior.

Um esquema de um trecho da parede de um trocador qualquer com a região interna (cinza na imagem) mais quente, está desenhado abaixo:

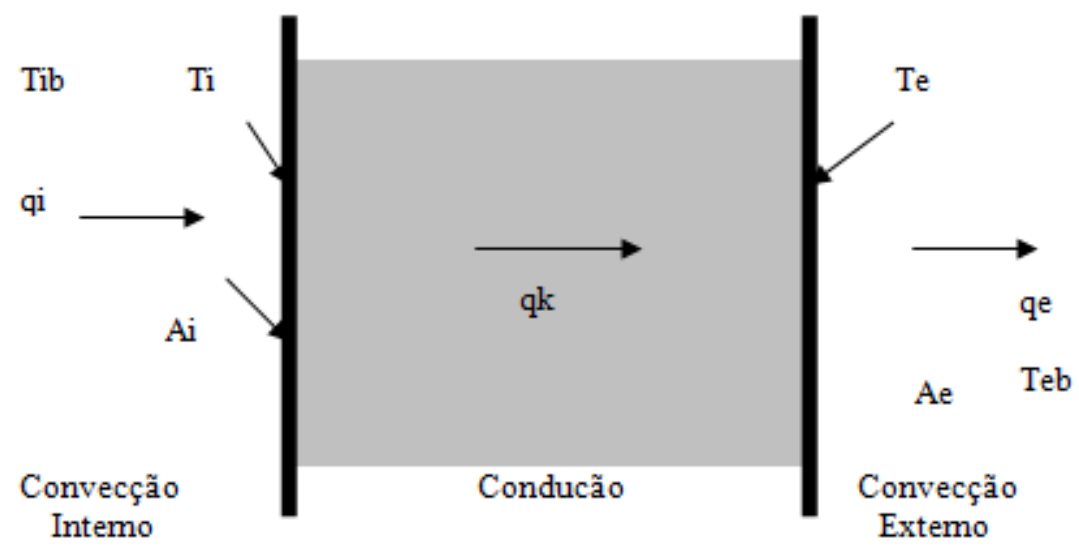

Figura 2 - Esquema da parede de um trocador 


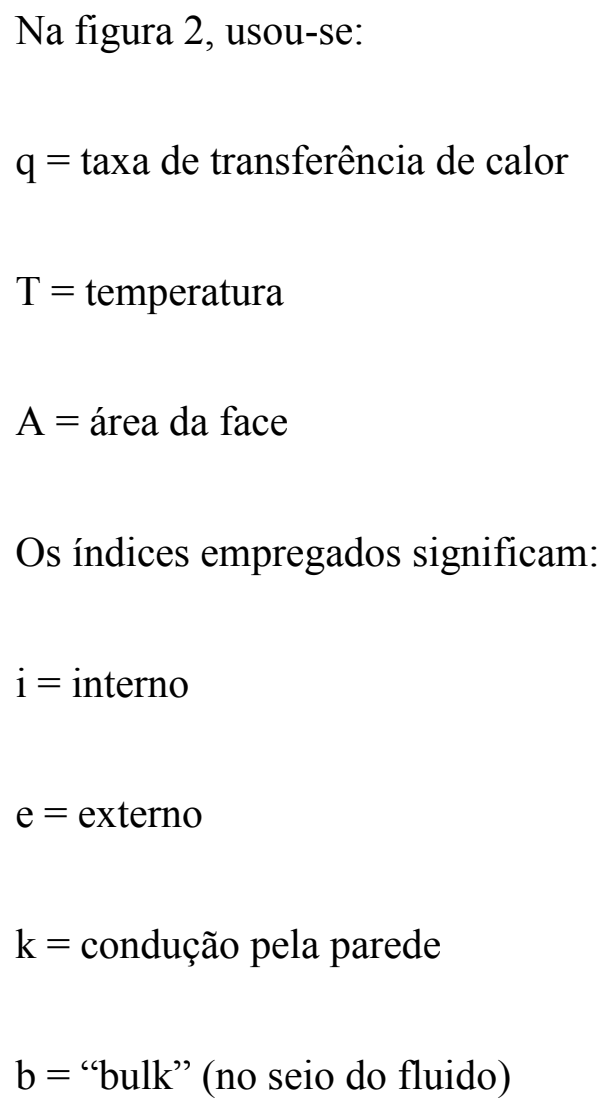

Quando temos mais de uma etapa de transferência de calor envolvida, é instrumento facilitador dos cálculos empregarem-se um coeficiente de transferência dito global ou integral. A fórmula que permite calcular tal coeficiente varia com as características do problema envolvido, porém a equação é deduzida de modo que sempre seja verdadeira a expressão:

$$
q_{T O T A L}=A \cdot U \cdot \Delta T
$$

Onde:

$\mathrm{q}_{\mathrm{TOTAL}}=$ calor total transferido

$\mathrm{U}=$ coeficiente global de transferência de calor 
$\mathrm{A}=$ área de troca de referência, empregada na dedução de $\mathrm{U}$

$\Delta \mathrm{T}=$ diferença de temperatura entre o fluido quente e o fluido frio

A forma da expressão do coeficiente global depende da forma das expressões das taxas de transferência para cada um dos mecanismos envolvidos.

\section{Transferência de Calor por Condução}

No estudo da transferência de calor, condução térmica é a transferência de energia térmica entre átomos ou moléculas vizinhas em uma substância devido a um gradiente de temperatura. Calor pode ser transferido também por radiação ou convecção, e normalmente mais que um destes processos ocorre simultaneamente.

O fluxo de calor sempre ocorre a partir de uma região de maior temperatura para uma região de baixa temperatura. O sentido é de equalizar as diferenças de temperatura.

A propagação de calor por condução ocorre sem transporte de massa, ou seja, através de choques entre suas partículas ou intercâmbios energéticos dos átomos, moléculas e elétrons. A condução térmica pode ser interpretada como a transmissão passo a passo de agitação térmica: um átomo ou uma molécula transfere parte de sua energia cinética ao átomo vizinho, sendo assim um fenômeno de transporte de energia interna provocado pela heterogeneidade da agitação molecular. Este é um fenômeno termodinamicamente irreversível. 
Ao se considerar que a transferência de calor se dá por um tubo, e sendo assim é unidirecional pelo raio, regime permanente e sem geração de calor na parede. Sob tais condições se emprega a lei de Fourier:

$$
q_{k}=-k A \frac{d T}{d r}
$$

Onde:

$q_{k}=$ taxa de transferência de calor por condução

$\mathrm{k}=$ um coeficiente de transferência por condução (condutividade térmica)

$\mathrm{r}=$ raio do tubo

Observe que a transferência de calor ocorre da região de maior temperatura para a de menos temperatura. Desta forma, dT é negativo. Observe também que a área normal ao sentido do escoamento de calor depende do raio.

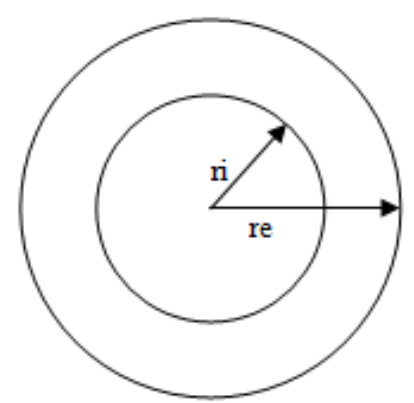

Figura 3 - Esquema dos raios de um tubo 
Efetuando a simplificação de que a condutividade térmica é constante com a temperatura, podemos encontrar a expressão finita da taxa de transferência de calor por condução através de um tubo.

$$
q_{k}=-k(2 \pi r L) \frac{d T}{d r}
$$

Onde L é o comprimento total do tubo.

$$
q_{k} \int_{i}^{e} \frac{d r}{r}=-k 2 \pi L \int_{i}^{e} d T
$$

Simplificando (4), teremos:

$$
q_{k} \ln \left(\frac{r e}{r i}\right)=-k 2 \pi L(T e-T i)
$$

Separando a variável “ $q_{k}$ ” de (5): 


$$
q_{k}=\frac{-2 \pi L k(T e-T i)}{\ln (r e / r i)}
$$

\section{Transferência de Calor por Convecção}

A Convecção é um processo de transporte de massa caracterizado pelo movimento de um fluido devido à sua diferença de densidade, especialmente por meio de calor. A convecção é um dos principais modos de transferência de calor e transferência de massa. Transferência convectiva de calor e massa ocorre tanto através de difusão - o movimento Browniano aleatório de partículas individuais no fluido - e, por advecção, na qual matéria ou o calor são transportados pelo movimento de grande escala de correntes no fluido. No contexto da transferência de calor e massa, o termo "convecção" é usado para referir-se à soma de transferências advectivas e difusivas. O coeficiente de transferência de calor por convecção " $h$ " é definido de modo que a expressão abaixo seja verdadeira:

$$
q_{\text {CONVECÇÃO }}=h A \Delta T
$$

Onde:

$q_{\text {CONVECÇÃO }}=$ taxa de transferência de calor por convecção

$\mathrm{h}=$ coeficiente de transferência de calor por convecção 
Desta forma, pode-se exprimir a taxa de transferência de calor para o lado "interno" e o lado "externo", de onde ocorre a troca de calor (importante lembrar que o sinal das expressões é trocado caso o calor siga sentido inverso), na forma:

$$
\begin{aligned}
& q_{i}=h_{i} A_{i}\left(T_{i b}-T_{i}\right) \\
& q_{e}=h_{e} A_{e}\left(T_{e}-T_{e b}\right)
\end{aligned}
$$

\section{Dedução do Coeficiente Global de Transferência de Calor para Tubos}

O coeficiente de transferência térmica global "U" é a medida da habilidade global de uma série de barreiras condutivas e convectivas para transferir calor. Para o caso do trocador de calor, "U" pode ser usado para determinar a transferência de calor total entre as duas correntes no trocador de calor pela seguinte relação:

$$
Q=U A \Delta T_{L M}
$$

Onde:

$\mathrm{Q}=$ taxa de transferência térmica $(\mathrm{W})$ 
$\mathrm{U}=$ coeficiente de transferência de calor global $\left(\mathrm{W} /\left(\mathrm{m}^{2} \cdot \mathrm{K}\right)\right)$

$\mathrm{A}=$ área de superfície de transferência de calor $\left(\mathrm{m}^{2}\right)$

$\Delta T_{L M}=$ diferença de temperatura média logarítmica $(\mathrm{K})$

O coeficiente de transferência térmica global leva em conta os coeficientes de transferências térmicas individuais de cada corrente e a resistência do material do tubo. Pode ser calculado como o recíproco da soma de uma série de resistências térmicas:

$$
\frac{1}{U A}=\Sigma \frac{1}{h A}+\Sigma R
$$

Onde:

$\mathrm{R}=$ Resistência(s) ao fluxo de calor na parede do tubo (K/W)

O coeficiente de transferência de calor é o calor transferido por unidade de área por kelvin. Então as áreas são incluídas na equação como representando a área sobre a qual a transferência de calor toma lugar, para cada fluxo de corrente. As áreas de cada fluxo irão ser diferentes como representam a área de contato com o fluido de cada lado.

A resistência térmica devida à parede do tubo é calculada pela seguinte relação abaixo:

$$
R=\frac{x}{k \cdot A}
$$


Onde:

$\mathrm{x}=$ espessura da parede $(\mathrm{m})$

$\mathrm{k}=$ condutividade térmica do material $(\mathrm{W} /(\mathrm{m} \cdot \mathrm{K}))$

$\mathrm{A}=$ área total do trocador de calor $(\mathrm{m} 2)$

A diferença de temperatura total entre o fluido quente e o frio é igual a somatória das diferenças de temperatura em cada setor do sistema considerado:

$\Delta T_{\text {TOTAL }}=\Sigma \Delta T_{P A R C I A I S}$

Assim sendo, podemos explicitar a equação (13), dessa maneira:

$\Delta T_{T O T A L}=\left(T_{i b}-T_{i}\right)+\left(T_{i}-T_{e}\right)+\left(T_{e}-T_{e b}\right)$

Outra relação importante é:

$\Delta T_{T O T A L}=\frac{q_{T O T A L}}{A_{j .} U_{j}}$ 
Onde:

$\mathrm{Uj}$ = coeficiente global de troca térmica empregando uma dada área de referência

$\mathrm{Aj}=$ área de referência

Associando (14) e (15) com (3) e (7), obtemos:

$\Delta T_{\text {TOTAL }}=\frac{q_{\text {TOTAL }}}{A j \cdot U j}=\frac{q_{i}}{h i \cdot A i}+\frac{q \cdot k \cdot \ln \left(\frac{r e}{r i}\right)}{2 \cdot \pi \cdot L \cdot k}+\frac{q_{e}}{h e \cdot A e}$

Mas o regime é permanente. Não ocorre acúmulo de calor em nenhum setor do sistema considerado. Assim, a taxa de transferência de calor é a mesma em cada setor e igual à taxa global de transferência. Simplificando (16), se obtém:

$\frac{1}{A_{J} U_{J}}=\frac{1}{h i A i}+\frac{\ln (r e / r i)}{2 \pi L k}+\frac{1}{h e A e}$

Em geral, a área adotada como referência é a área externa dos tubos:

$$
A_{J}=A e=2 \pi r_{e} L
$$


A expressão do coeficiente global de transferência de calor então se torna:

$$
\frac{1}{U_{e}}=\frac{2 \pi r_{e} L}{h_{i} 2 \pi r_{i} L}+\frac{2 \pi r_{e} L \ln (r e / r i)}{2 \pi L k}+\frac{2 \pi r_{e} L}{h_{e} 2 \pi r_{e} L}
$$

Simplificando (19), chega-se a:

$$
\frac{1}{U_{e}}=\frac{r_{e}}{h_{i} r_{i}}+\frac{r_{e} \ln (r e / r i)}{k}+\frac{1}{h_{e}}
$$




\section{NORMA: NBR ISO 1585}

Esta parte do relatório tem como objetivo elucidar o leitor sobre o que é a referida norma e onde a mesma se aplica no contexto deste trabalho. Visto que o trocador de calor precisa obedecer às exigências de temperaturas descritas na norma. Um breve resumo de pontos fundamentais para a construção do trocador de calor do condicionador de combustível é importante.

A NBR ISSO 1585 trata de "Veículos Rodoviários - Código de Ensaio de Motores Potência Líquida Efetiva". Essa norma foi formulada pela ABNT - Associação Brasileira de Normas Técnicas- em junho de 1996. A ABNT é o Fórum Nacional de Normalização, responsável pelo estudo e aprovação de novas normas ou revisões das mesmas.

A referida norma especifica um método de ensaio de motores projetados para veículos automotores, dessa maneira pode-se dizer que ela se aplica à avaliação do desempenho de motores a combustão interna, apenas no âmbito da potência liquida, cuja definição segundo a norma NBR ISO1585 é: "Potência obtida em uma bancada de ensaio, na saída da árvore de manivelas ou seu equivalente, na rotação correspondente do motor com o equipamento e aparelhos auxiliares relacionados na tabela 1" (a tabela 1 da norma contêm dados sobre a instalação de diversos equipamentos e componentes durante o ensaio).

O ensaio deve ser realizado com o acelerador plenamente acionado, no caso de motores de ignição por centelha. No caso de motores de ignição por compressão, a bomba injetora deve ser colocada com a posição fixa e plena carga. Em ambos os casos o motor precisa ser equipado conforme especificado na tabela 1 . 
Dentre as regras para a realização de ensaios descritas na norma, a que é realmente importante para a realização do presente trabalho de conclusão de curso são as temperaturas do combustível.

\section{Temperaturas do Combustível nos Ensaios}

Nos motores de ignição por centelha, a temperatura do combustível deve ser medida o mais próximo possível da injeção ou carburador. A temperatura deve ser mantida a $\pm 5 \mathrm{~K}$ da que foi especificada pelo fabricante. Caso não seja especificada, a temperatura deve ser de $298 \mathrm{~K} \pm 5$ K. A temperatura mínima que o combustível pode estar para a realização dos testes é a do ar ambiente.

Já no caso dos motores de ignição por compressão, a temperatura deve ser medida na entrada da bomba de admissão de combustível (pode ser em qualquer parte da bomba, caso haja solicitação do fabricante). A temperatura deve ser mantida a $\pm 3 \mathrm{~K}$ da estabelecida pelo fabricante. Em qualquer caso, a temperatura mínima na entrada da bomba é de $303 \mathrm{~K}$. Caso a temperatura do teste não seja especificado pelo fabricante, deve-se considerar $313 \mathrm{~K} \pm 3 \mathrm{~K}$. 


\section{DISPOSITIVO EXPERIMENTAL E PROCEDIMENTOS}

\section{MÉTODOS E PLANILHA UTILIZADOS PARA O DIMENSIONAMENTO}

Para realizar os cálculos, foi necessária a elaboração de uma planilha no Microsoft Office Excel que pudesse, com assertividade razoável, assegurar que o trocador dimensionado consegue manter o combustível nas temperaturas aceitas pela NBR ISO 1585 na realização dos ensaios com motores. Abaixo pode-se ver um print da memória de cálculo da planilha, que usando um método iterativo, onde se calcula as temperaturas do fluido a cada $10 \mathrm{~cm}$, permite uma análise dos dados para esoclher o comprimentro da serpentina que atende ao projeto.

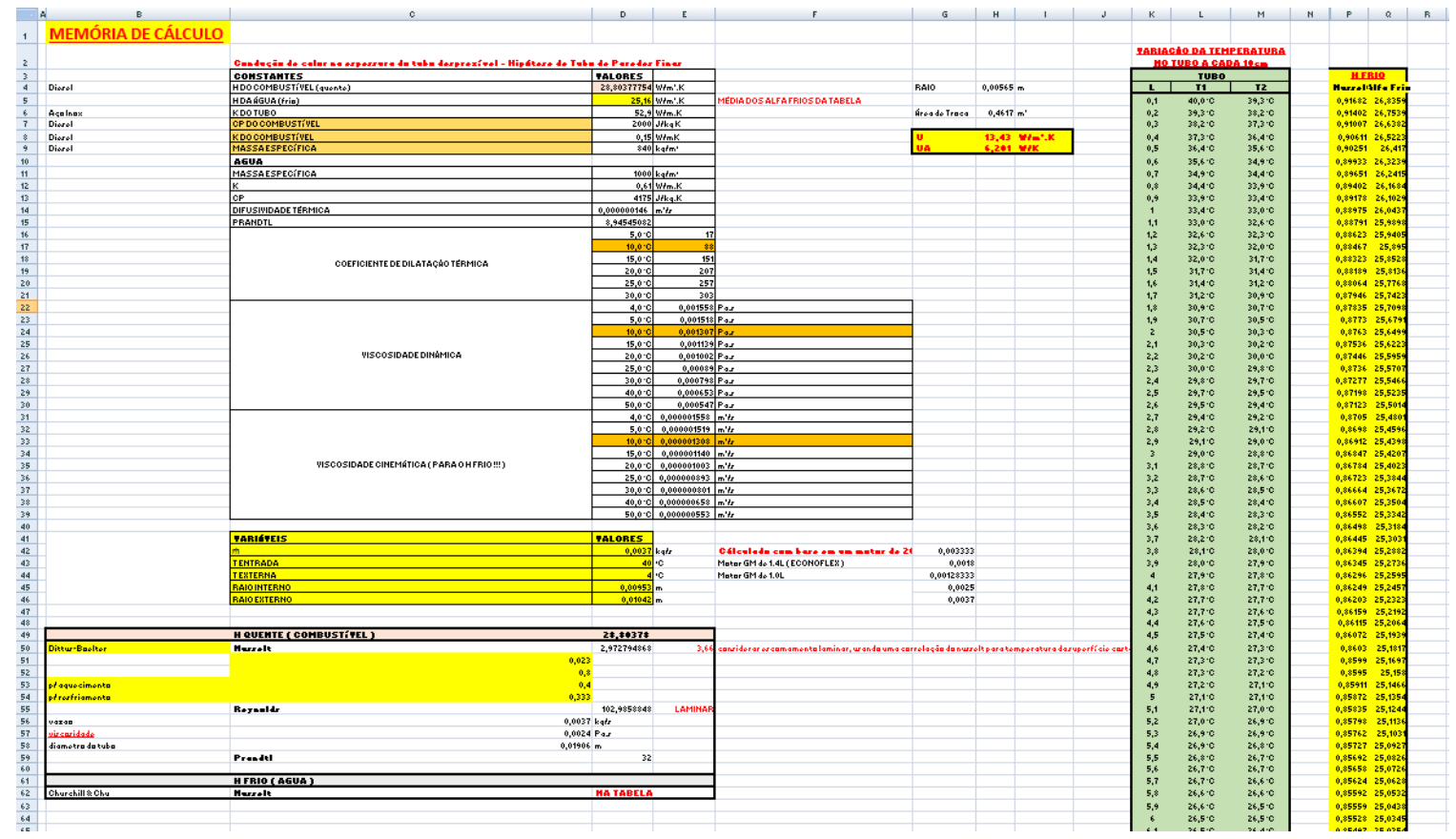

Figura 4 - Print da tela na planilha do Excel

Foram utilizados valores de referência utilizando o diesel como combustível. Outra consideração importante é que a condução de calor na espessura do tubo é desprezível, podendo 
assim ser utilizado a hipótese de tubos de paredes finas, pois a espessura do tubo é muito pequena em relação ao seu diâmetro interno. Sendo assim, teremos apenas duas únicas resistências térmicas equivalentes: uma devida à convecção interna e a outra à convecção externa.

A escolha de como seria o trocador a ser construído, foi feita levando em conta a simplicidade na construção e o preço, mas garantindo um funcionamento perfeito. Assim, definiu-se construir um trocador composto por uma serpentina e um vaso de pressão que comporta água gelada em seu interior, de modo a se ter um banho térmico.

O método utilizado para o dimensionamento é o descrito anteriormente nesse relatório. Durante o cálculo, foi necessário se definir as correlações do número de Nusselt que seriam utilizadas para chegar a um coeficiente convectivo de transferência de calor para o "lado frio" e o "lado quente" do trocador.

Para o coeficiente convectivo do combustível (lado quente), utilizou-se uma correlação de Nusselt para a temperatura da superfície constante, desde que o escoamento interno seja sempre laminar. Seu valor é 3,66.

O Coeficiente Convectivo da água (lado frio) é mais complicado de se calcular, pois depende de algumas variáveis. Como não ocorre fluxo de água no trocador, pode-se considerar que ocorre convecção natural. Apesar de ser uma aproximação grosseira, considerar a serpentina como um tubo circular horizontal não infringirá em um grande problema ao dimensionamento do trocador. Assim, a correlação utilizada foi a proposta por Morgan, V. T., em "The Overall Convective Heat Transfer from Smooth Circular Cylinders": 
$\overline{N u_{D}}=C \cdot R a_{D}{ }^{n}$

Onde:

$N u_{D}=$ Número de Nusselt médio

$R a_{D}=$ Número de Rayleigh

$\mathrm{C}=$ Coeficiente dado pelo autor.

$\mathrm{n}=$ Coeficiente dado pelo autor.

Os valores dos coeficientes dados por Morgan são:

\begin{tabular}{|c|c|c|}
\hline$R a_{D}$ & $\mathbf{C}$ & $\mathbf{N}$ \\
\hline $10^{-10}-10^{-2}$ & 0,675 & 0,058 \\
\hline $10^{-2}-10^{2}$ & $1,1,02$ & 0,148 \\
\hline $10^{2}-10^{4}$ & 0,850 & 0,188 \\
\hline $10^{4}-10^{7}$ & 0,480 & 0,250 \\
\hline $10^{7}-10^{12}$ & 0,125 & 0,333 \\
\hline
\end{tabular}

Tabela 1 - Coeficientes para Nusselt propostos por Morgan

Após a definição do material a ser utilizado na serpentina e no vaso de pressão descritos no próximo capítulo - chegou-se à definição de que seriam necessários $13 \mathrm{~m}$ de comprimento na serpentina, para garantir que o combustível atenderia a norma NBR ISO 1585.

Com esses dados, temos então que:

$\mathrm{U}=13,4 \mathrm{~W} / \mathrm{m}^{2} . \mathrm{K}$ 


\author{
$\mathrm{UA}=6,2 \mathrm{~W} / \mathrm{K}$ \\ Onde: \\ $\mathrm{U}=$ Coeficiente de Transferência Térmica Global \\ UA $=$ Coeficiente de Transferência Térmica por unidade de Área
}

MONTAGEM DO TROCADOR DE CALOR

\title{
Definição do Material a ser Utilizado
}

No momento de decidir qual material utilizar na construção do trocador de calor, algumas questões foram levantadas. Deve-se considerar usar materiais que suportem ambientes corrosivos, sejam resistentes à água, duráveis e inertes ao ambiente que estão.

Após o dimensionamento se verificou que é necessário 13 metros de comprimento na serpentina, ao utilizar-se 3/8" de diâmetro do tubo. A espessura da parede é de 0,89 milímetros. O material escolhido foi aço inoxidável, pois não tem problema com água nem combustível e tem durabilidade altíssima. No caso do vaso de pressão - de baixa pressão, não ultrapassando 4 bar - não era necessário a definição de uma tamanho para o mesmo - visto que é um banho e assim não ocorre corrente dessa água na carcaça - entretanto deve-se tomar cuidado com a carga térmica no interior do banho, para assegurar que a temperatura se manterá relativamente constante na maior parte do tempo. O material escolhido primeiramente foi o aço inoxidável. No 
entanto, o preço do vaso de pressão ficou muito alto e se fez necessário a escolha de uma alternativa economicamente mais viável.

A alternativa para o aço inoxidável no vaso de pressão foi o Polietileno, mais especificamente o PEAD (Polietileno de Alta Densidade). Esse material é: atóxico, leve, inerte (ao conteúdo), impermeável, barato, resistente a altas temperaturas e resistente à tração, compressão e tensões altas. Tubos e conexões necessários foram feitos utilizando materiais comuns de obra, como canos de PVC (Policloreto de Vinila).

\section{Construção do Trocador de Calor}

Para a construção do trocador de calor comprou-se uma serpentina comum de aço inoxidável, utilizada em chopeiras. Já no caso do vaso de pressão, foi preciso mandar fabricar um sob medida, visto que não foi possível encontrar no mercado um que atendesse as necessidades do projeto.

O vaso de pressão - de baixa pressão, pois a pressão não ultrapassa em nenhuma hipótese 4 bar - foi construído com um pedaço de tubo de PEAD, flangeado nas duas extremidades. As tampas são aparafusadas e presas com arruela e porca. Após a construção, foi necessário testar se haveriam vazamentos no trocador, que felizmente não ocorreram. 


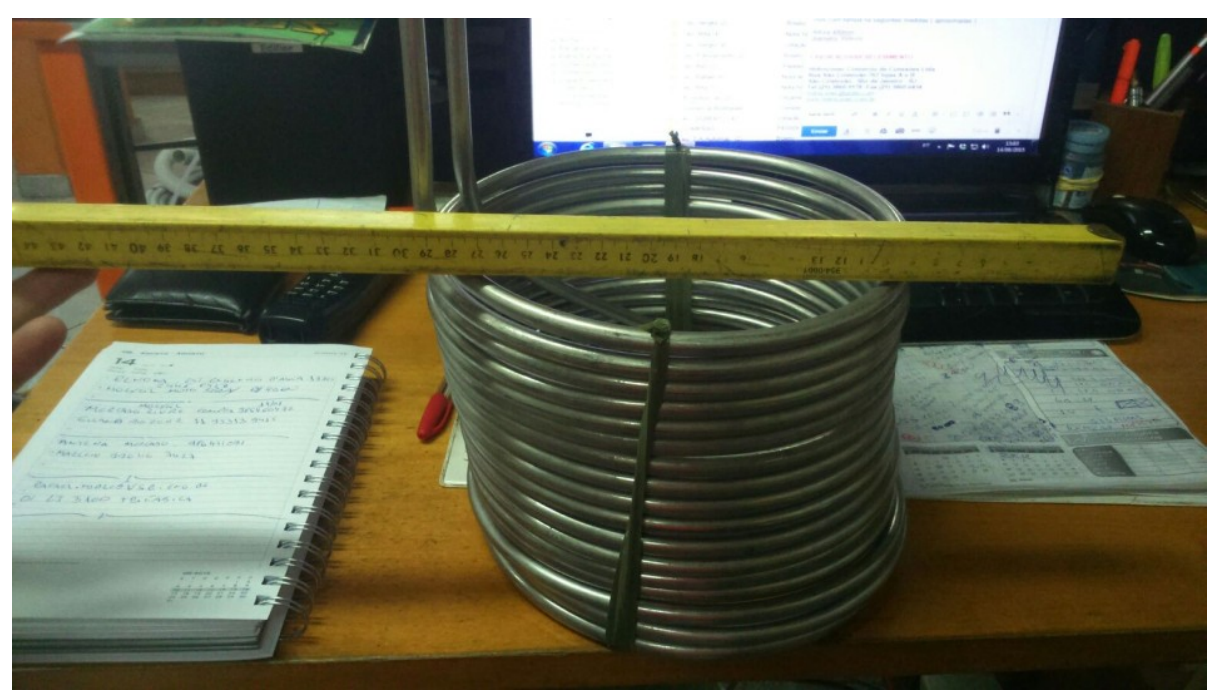

Figura 5 - Serpentina de Aço Inox

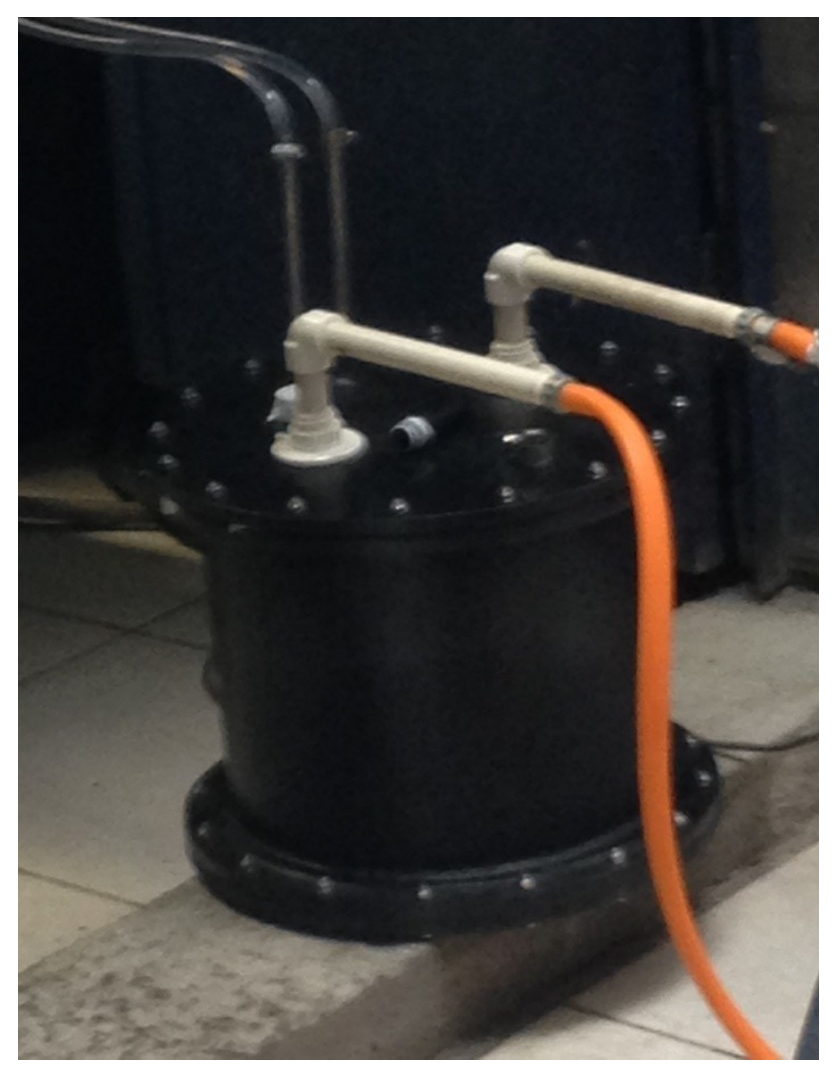

Figura 6 - Trocador de Calor 


\section{REALIZAÇÃO DO TESTE DO PROJETO}

Para a realização dos testes, utilizou-se o segundo andar do LEV Puc-Rio (Laboratório de Engenharia Veicular da Puc-Rio), onde foram montados todos os acessórios necessários. Um banho térmico foi utilizado para simular o combustível aquecido, entretando, devido a problemas com local para testes e equipamentos, não foi possível a realização dos testes utilizando combustível, e por isso utilizou-se água aquecida à $50^{\circ} \mathrm{C}$ simulando o combustível que necessitaria ser resfriado para atender as exigências da norma NBR ISO 1585.

Para medir a temperatura, foi elaborada a utilização de um controlador ligado a um termopar PT100, medindo na saída da serpentina. Outros componentes como uma válvula solenoide por exemplo, foram utilizados também. O esquema abaixo é um desenho de como foi feito a montagem dos equipamentos e principais acessórios necessários para a realização dos testes:

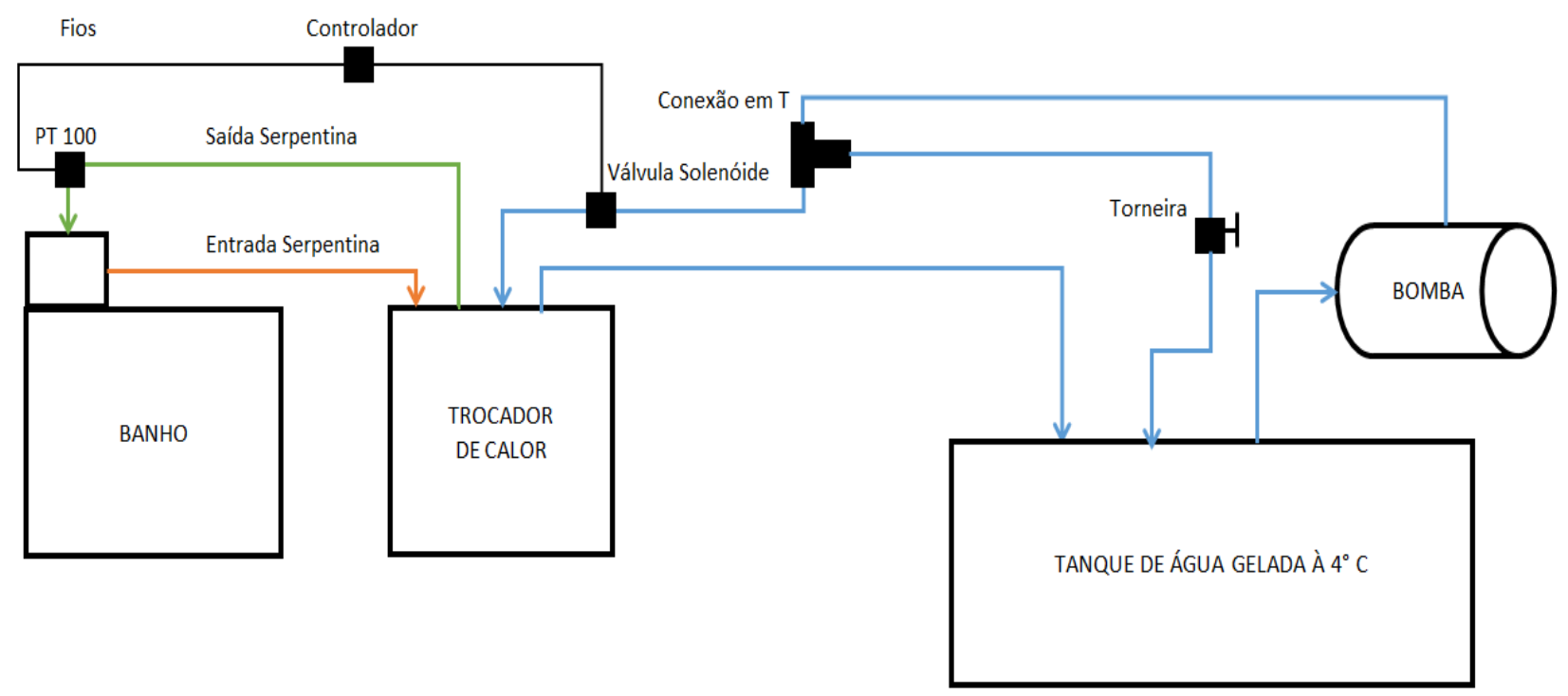

Figura 7 - Esquema da montagem do teste 
Um tanque de 1301 foi utilizado para conter água gelada à aproximadamente $4{ }^{\circ} \mathrm{C}$, de modo que foram necessários $75 \mathrm{~kg}$ de gelo para manter o tanque a essa temperatura durante todo o teste.

A válvula solenoide no esquema tem a função de fechar a entrada de água na "carcaça" do trocador, sempre que o controlador, através do PT100, perceba que a temperatura de saída está abaixo de $25^{\circ} \mathrm{C}$ (temperatura configurada no controlador).

Assim sendo, o objetivo do teste era baixar a água que vinha do banho a $50^{\circ} \mathrm{C}$ para $25^{\circ}$ $\mathrm{C}$, decrescendo a temperatura do banho $5^{\circ} \mathrm{C}$ por vez.

A bomba descrita no desenho é uma bomba d'água comum, onde utilizando a conexão em "T" e a válvula de gaveta (torneira), foi possível manter uma vazão constante de aproximadamente $0,005 \mathrm{~kg} / \mathrm{s}$. A indução da perda de carga pela válvula permitiu que fosse possível regular a vazão, entretanto com pouca precisão.

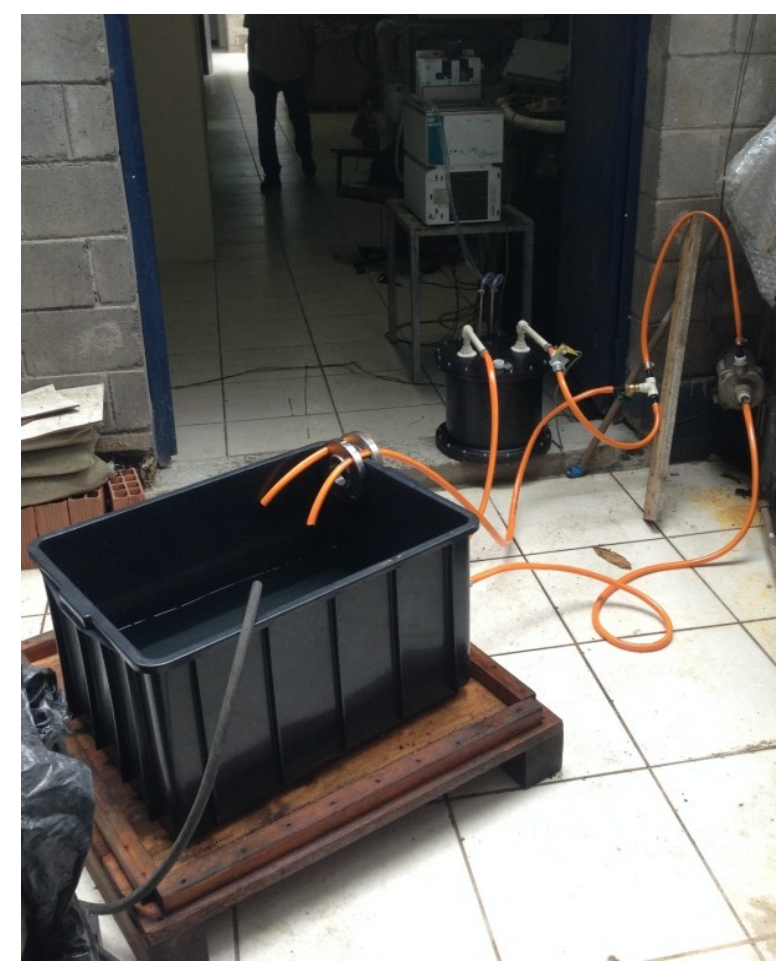

Figura 8 - Sistema de teste montado 


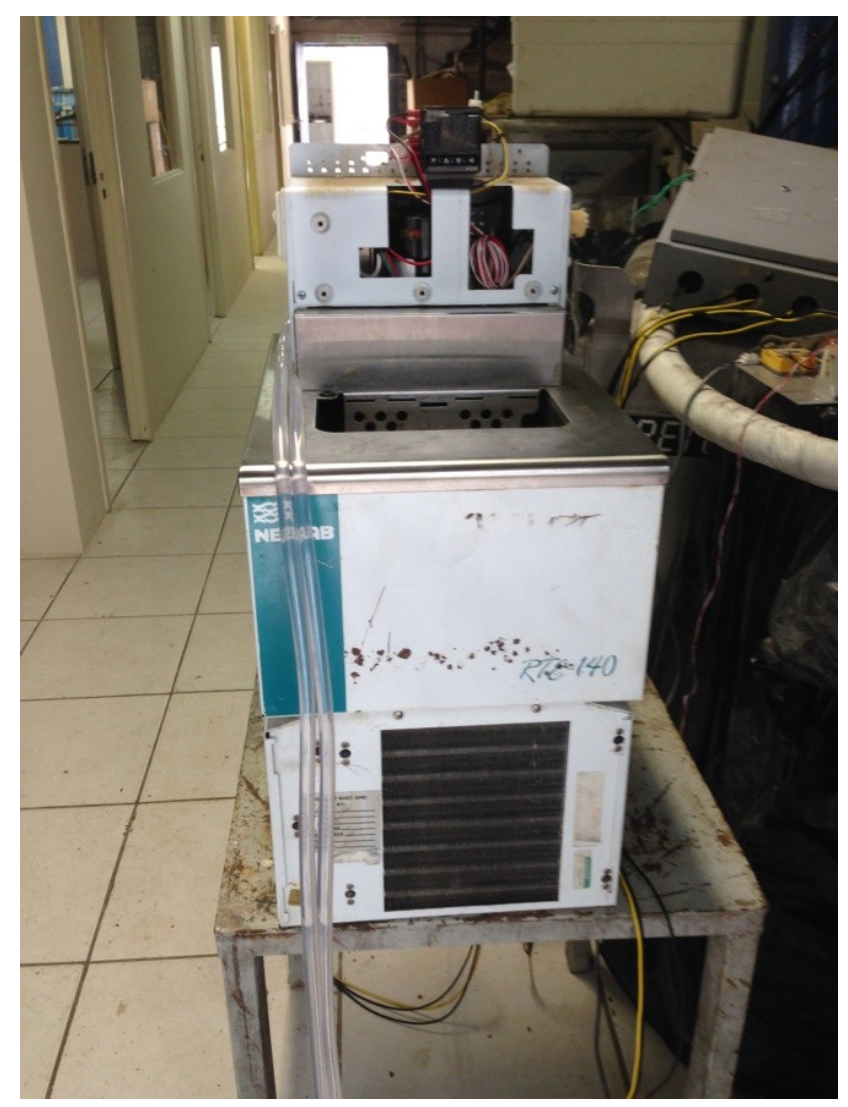

Figura 9 - Banho térmico

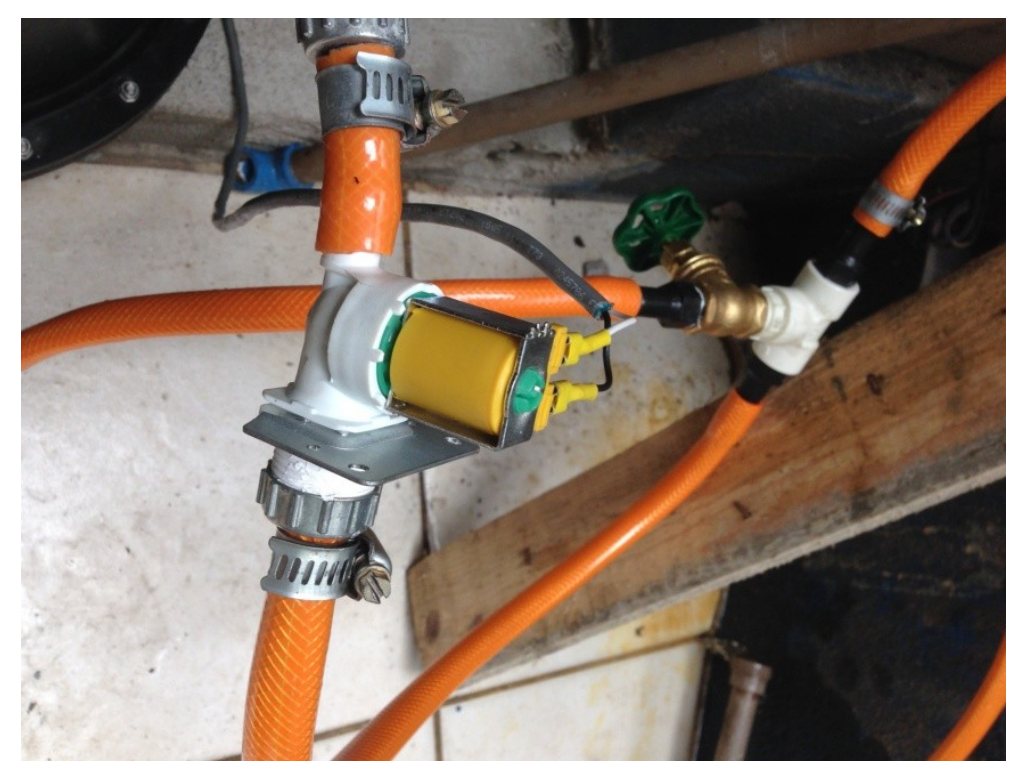

Figura 10 - Válvula Solenóide, conexão em T e Válvula de gaveta (Torneira) 


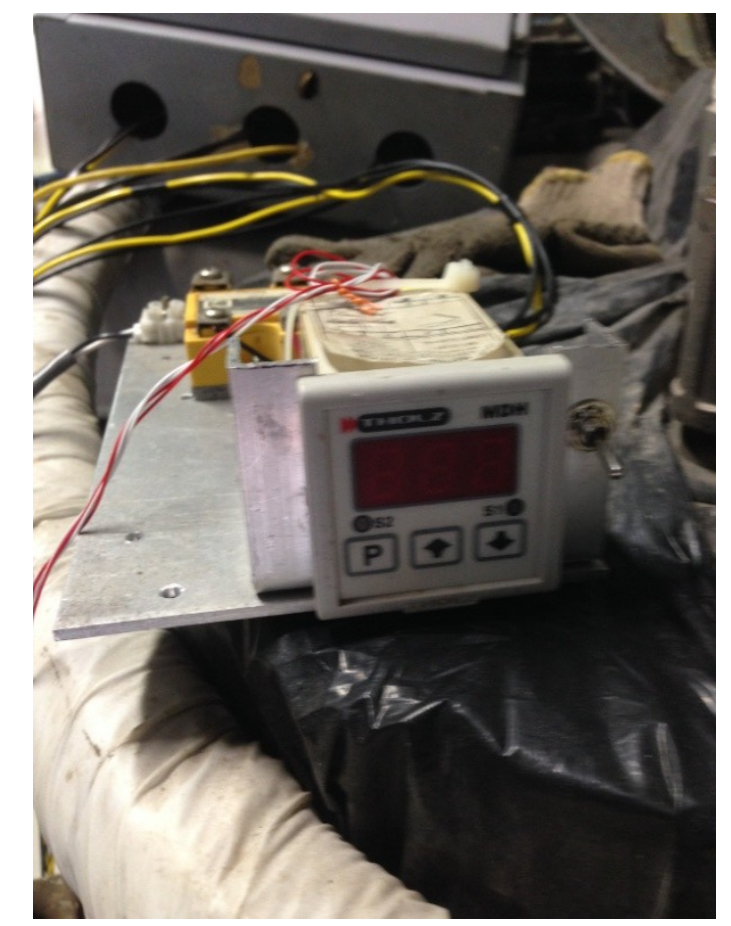

Figura 11 - Controlador da válvula solenoide e do PT100

Ao tentar realizar o teste, constatou-se que a potência do banho, que deveria aquecer a água a $50{ }^{\circ} \mathrm{C}$ era insuficiente. $\mathrm{O}$ banho possui $1000 \mathrm{~W}$ de potência, mas não conseguia manter essa temperatura quando á saída do trocador era aberta. A temperatura se mantinha a no máximo $35{ }^{\circ} \mathrm{C}$.

Para solucionar o problema apresentado, utilizaram-se duas resistências elétricas que ao somar as suas potências, adicionaram $1800 \mathrm{~W}$ ao banho. As duas foram ligadas ao controlador do próprio banho, para que fossem controladas junto à sua própria resistência. Após esse ajuste, o banho passou a ter $2800 \mathrm{~W}$ de potência, possibilitando a realização dos testes. 


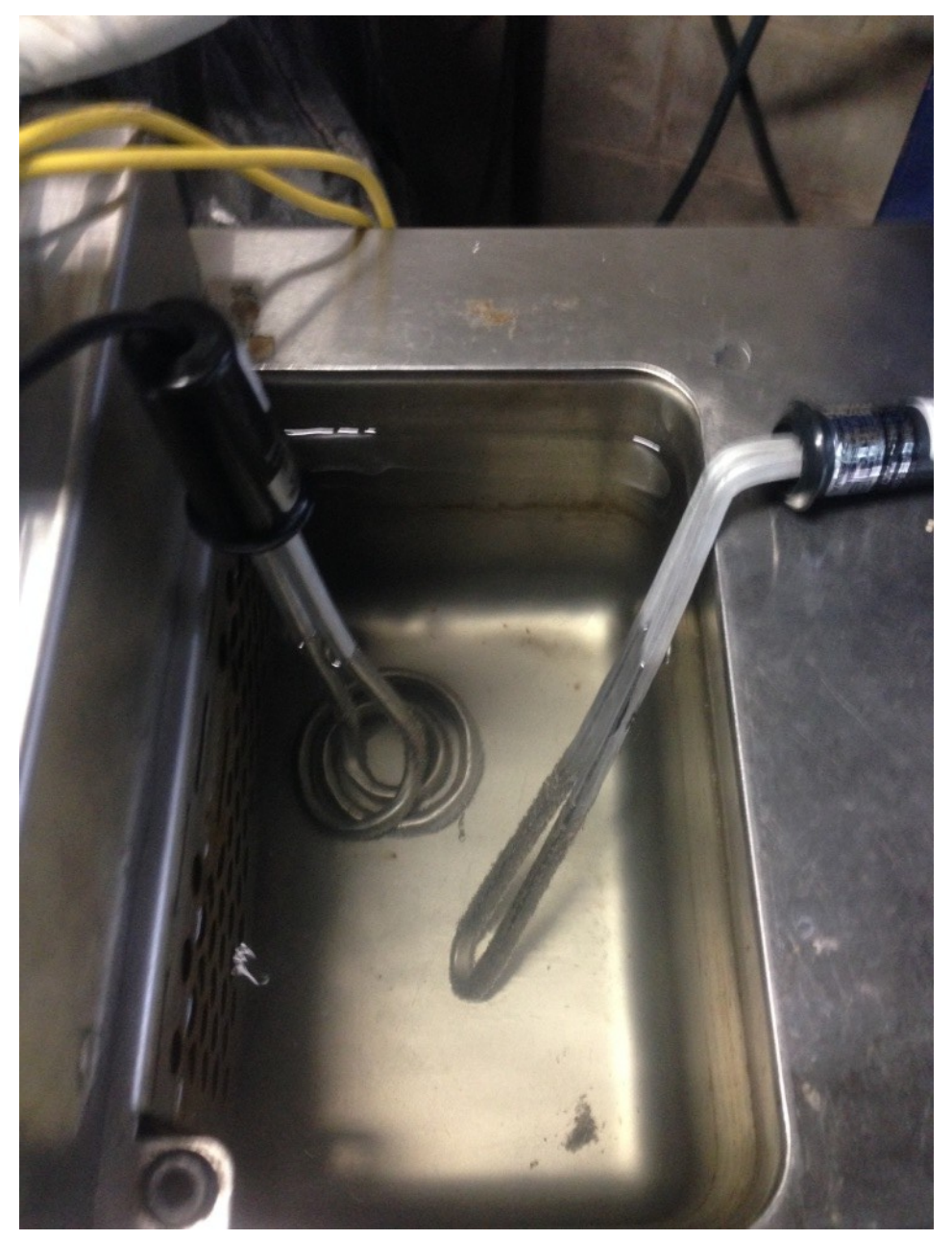

Figura 12 - Resistências adicionais no banho 


\section{RESULTADOS}

\section{RESULTADO EXPERIMENTAL}

O teste foi repetido três vezes, partindo sempre do banho à $50{ }^{\circ} \mathrm{C}$ e decrescendo até atingir $25^{\circ} \mathrm{C}$, sendo realizadas medições a cada $5{ }^{\circ} \mathrm{C}$. Abaixo se pode ver a tabela dos valores de temperatura medidos pelo PT100 (termopar):

\begin{tabular}{|c|c|c|c|c|}
\hline \multicolumn{5}{|c|}{ TABELA DE RESULTADOS EXPERIMENTAIS $\left({ }^{\circ} \mathrm{C}\right)$} \\
\hline TEMP. DE ENTRADA & TESTE & & & \\
\hline & 1 & 2 & 3 & MÉDIA \\
\hline 50,0 & 35,2 & 33,6 & 31,2 & 33,3 \\
\hline 45,0 & 30,0 & 28,6 & 26,9 & 28,5 \\
\hline 40,0 & 27,0 & 26,0 & 25,7 & 26,2 \\
\hline 35,0 & 25,0 & 25,0 & 25,0 & 25,0 \\
\hline 30,0 & 25,0 & 25,0 & 25,0 & 25,0 \\
\hline 25,0 & 25,0 & 25,0 & 25,0 & 25,0 \\
\hline
\end{tabular}

Tabela 2 - Resultados Experimentais

Podem-se colocar de forma gráfica esses valores a fim de possibilitar uma visão melhor do que está ocorrendo. Desse modo, teremos: 


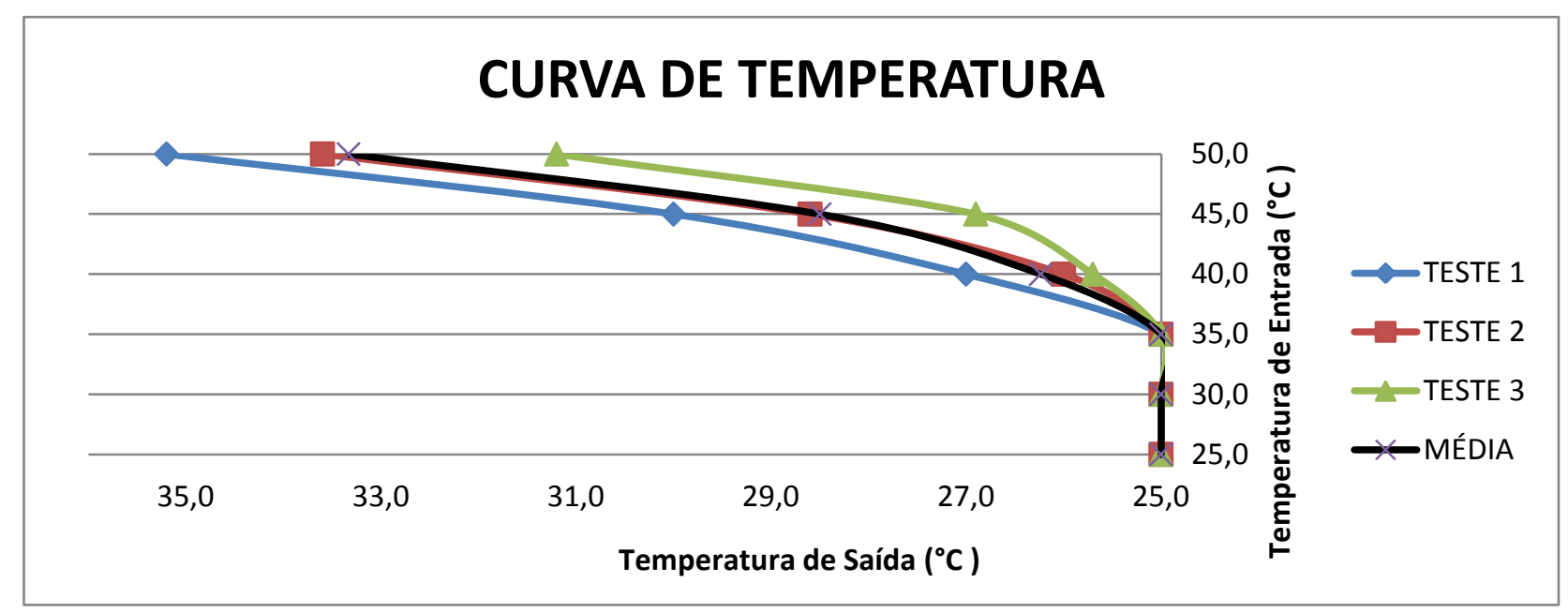

Figura 13 - Curva de temperatura dos testes

\section{COMPARAÇÃO ENTRE RESULTADO TEÓRICO E EXPERIMENTAL}

Para analisar melhor os resultados obtidos, é preciso comparar se a tabela de Excel elaborada foi capaz de dimensionar com assertividade o perfil de temperatura na serpentina. Abaixo há uma comparação entre a média dos valores experimentais e o valor teórico gerado na planilha ao se simular as mesmas condições do teste:

\begin{tabular}{|r|r|r|r|}
\hline TEMP. DE ENTRADA & EXPERIMENTAL & TEÓRICO & \% ERRO \\
\hline 50,0 & 33,3 & 33,5 & 0,5 \\
\hline 45,0 & 28,5 & 30,4 & 6,5 \\
\hline 40,0 & 26,2 & 27,1 & 3,3 \\
\hline 35,0 & 25,0 & 25,0 & 0,0 \\
\hline 30,0 & 25,0 & 25,0 & 0,0 \\
\hline 25,0 & 25,0 & 25,0 & 0,0 \\
\hline
\end{tabular}

Tabela 3 - Erro entre experimental e teórico 
Percebe-se que o erro dos valores experimentais é relativamente baixo em relação ao projetado. A maior variação foi de $6,5 \%$, representando uma assertividade que é satisfatória e suficiente para a finalidade do trocador projetado.

Para melhor visualização do erro pode-se fazer um gráfico comparativo entre a curva de temperatura experimental e a teórica:

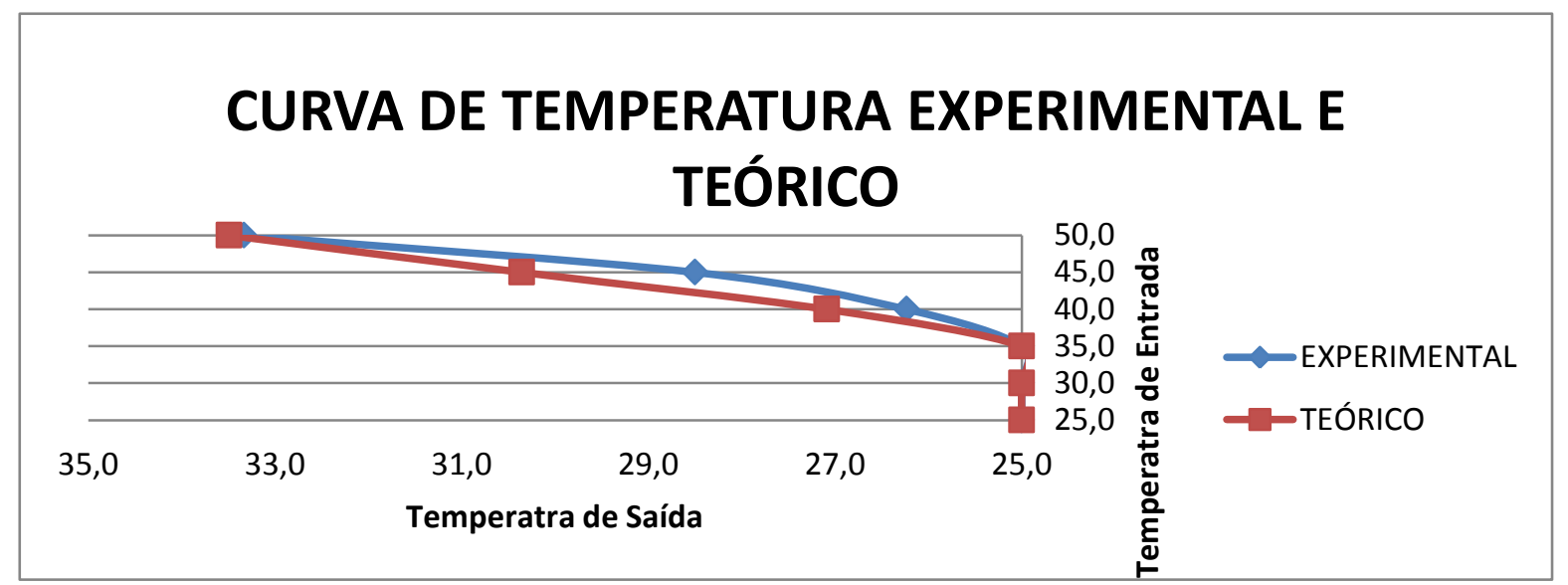

Figura 14 - Gráfico de temperatura experimental e teórica 


\section{CONCLUSÃO}

Conforme os resultados apresentados no texto, o método de dimensionamento do trocador de calor apresentado se mostrou eficiente. Pode-se assim garantir que o trocador de calor possa atender as especificidades da norma NBR ISO 1585 - "Veículos Rodoviários Código de Ensaio de Motores - Potência Líquida Efetiva" para ser utilizado em um Sistema Condicionador de Combustível.

O objetivo desse condicionador de combustível será o de realizar ensaios em motores de combustão interna, por centelha ou com ignição por compressão, nos futuros laboratórios do LEV no município de Xerém, estado do Rio de Janeiro.

Pessoalmente, esse trabalho me possibilitou testar conhecimentos adquiridos durante o curso de Engenharia Mecânica na PUC-Rio. Conhecimentos adquiridos em "Mecânica dos Fluidos", "Transferência de Calor e Massa" e "Projeto de Sistemas Térmicos" foram os que tiveram maior relevância durante a realização desse Projeto de Conclusão de Curso. 


\section{BIBLIOGRAFIA}

1. Fox, R. W.; Mcdonald, A. T.; Pritchard, P. T., -“Introdução à Mecânica dos Fluidos”, 6.ed., LTC- Livros Técnicos e Científicos, 2006

2. Incropera, F. P; Dewitt, D. P.; Bergman, T.L.; Lavine, A. S., - "Fundamentos de Transferência de Calor e Massa”,6. ed., LTC- Livros Técnicos e Científicos, 2007.

3. Milcent, P. F., - "Tópicos dos Conhecimentos Básicos no Estudo de Trocadores de Calor”, Universidade Federal do Paraná - Departamento de Engenharia Química, 2007.

4. NBR ISO 1585; "Veículos Rodoviários - Código de Ensaio em Motores - Potência Liquida Efetiva", ABNT, 1996.

5. Van Wylen, G; Sonntag, R. E.; Borgnakke, C., - "Fundamentos da Termodinâmica", 6. ed., LTC- Livros Técnicos e Científicos, 2003. 